\title{
A Comparison of the Anorexic Effects of Chicken, Porcine, Human and Bovine Insulin on the Central Nervous System of Chicks
}

\author{
Jun-ichi Shiraishi ${ }^{1}$, Kouchi Yanagita ${ }^{1}$, Fumiya Nishikawa ${ }^{1}$, Yuki Tahara ${ }^{1}$, \\ Masanori Fujita ${ }^{1}$, John P. McMurtry ${ }^{2}$ and Takashi Bungo ${ }^{1}$ \\ ${ }^{1}$ Laboratory of Animal Behavior and Physiology, Graduate School of Biosphere Science, \\ Hiroshima University, Higashi-Hiroshima 1-4-4 Kagamiyama 739-8528, Japan \\ ${ }^{2}$ United States Department of Agriculture, Agricultural Research Service, Animal and Natural Resources Institute, \\ Animal Biosciences and Biotechnology Laboratory, 10300 Baltimore Avenue, Building 200, \\ Room 206, BARC-east Beltsville, MD 20705-2350, USA
}

\begin{abstract}
The aim of the present study was to determine if some naturally-occurring substitutions of amino acid residues of insulin could act differentially within the central nervous system (CNS) of neonatal chicks to control ingestive behavior. Intracerebroventricular (ICV) administration of chicken insulin (20 ng) inhibited food intake in ad libitum chicks over the 120-min experiment period. A lower dose $(2 \mathrm{ng})$ also shows a suppressive effect at 60 min post-injection, but not at 30 and $120 \mathrm{~min}$. Similar to chicken insulin, a higher dose of porcine insulin $(20 \mathrm{ng})$ significantly inhibited food intake at 60 and 120 min post-injection, but a significant difference is not detected at $30 \mathrm{~min}$ post-injection. Treatment with human and bovine insulin had no effect in this study. Finally, we compared the effect of ICV injection of chicken and porcine insulin on food consumption in starved chicks. The results of the present study indicate that chicken insulin has a higher potent ability to depress feeding behavior in the CNS compared with porcine, human, and bovine insulin. Therefore, it seems that the ranking in order of potency of the insulins on the anorexic effect in neonatal chicks is chicken insulin $>$ porcine insulin $>$ human insulin $>$ bovine insulin. It is suggested that the $8^{\text {th }}-10^{\text {th }}$ amino acids of the A-chain and/or the C-terminal amino acid of the B-chain in insulin have an important role in bioactivity in the CNS with special reference to feeding behavior.
\end{abstract}

Key words: amino acid sequence, central nervous system, chick, food intake, insulin

J. Poult. Sci., 46: 144-148, 2009

\section{Introduction}

The chicken preproinsulin gene has been cloned and characterized (Smith, 1966; Perler et al., 1980). Like mammalian insulin, chicken insulin contains two polypeptide chains: A (21 amino acids) and B (31 amino acids) linked by two disulfide bonds (Smith, 1966). A third disulfide bond is present within the A-chain. The differences in amino acid sequences between chicken and mammalian insulins were confined to positions 8,9 and 10 of the A-chain (A8-A10) and 1, 2, 27 and 30 of the B-chain (B1, B2, B27 and B30) of the molecule (Fig. 1: Harris et al., 1956; Ishihara et al., 1958; Nicol and Smith, 1960). Although these differences between avian and mammalian insulin are small in relation to the whole molecule, it is well known that these differences affect the immunological

Received: December 11, 2008, Accepted: January 14, 2009

Correspondence: Dr. T. Bungo, Laboratory of Animal Behavior and Physiology, Graduate School of Biosphere Science, Hiroshima University, Higashi-Hiroshima 1-4-4 Kagamiyama 739-8528, Japan.

(E-mail: bungo@hiroshima-u.ac.jp) properties and biological potency (Hazelwood et al., 1968; 1971; Simon et al., 1974; 1977; McMurtry et al., 1983).

The insulin receptor is a transmembrane glycoprotein composed of two $\alpha$ subunits and two $\beta$ subunits linked by the disulfide bonds. There are two isoforms in the $\alpha$ subunits: one is expressed predominantly in the central nervous system (CNS) and hematopoietic cell, while the other is in the peripheral tissues, such as adipose tissue, liver and muscle (Moller et al., 1989). Tissue-specific responsiveness to stimulation by insulin is caused by this difference in $\alpha$ subunits (Mosthaf et al., 1990). In chickens, although there does not seem to be any difference in the function of the $\beta$ subunits of the insulin receptor in the CNS to those in the peripheral tissues (Kato et al., 2000), the binding sites and/or the capacity of the $\alpha$ subunits of the central insulin receptor may be different from those in peripheral tissues because the molecular mass of $\alpha$ subunits in the CNS is smaller than those in the liver (Simon and LeRoith, 1986). Intracerebroventricular (ICV) administration of mammalian insulin inhibits feeding behavior in chicks (Shiraishi et al., 2008a, b), and the insulinergic 


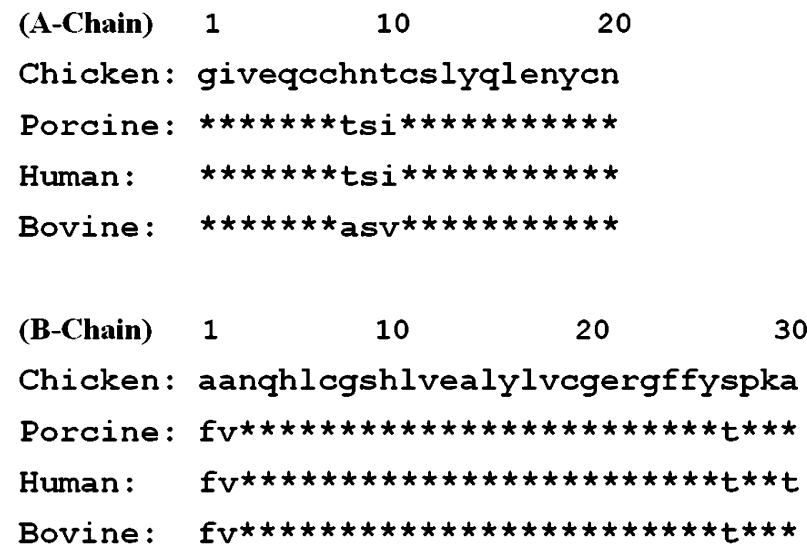

Fig. 1. Amino acid sequences of insulin A-chain (1-21) and B-chain (1-30) in chicken, porcine, human and bovine insulin. Asterisks show common amino acids.

system is important in the central regulation of feeding behavior in birds. There is, however, no information on whether differences in the effect of some substitutions of amino acid residues of insulin on feeding behavior exist in the CNS of chicks.

The aim of this study was to determine if some naturallyoccurring substitutions of amino acid residues of insulin could act differentially within the CNS of neonatal chicks to control ingestive behavior. We examined (1) whether insulin (chicken, porcine, human or bovine) administered ICV decreases food consumption in chicks under ad libitum conditions, and (2) whether chicken insulin is more effective than porcine insulin in controlling feeding behavior in fasted chicks.

\section{Materials and Methods}

\section{Animals}

Day-old male Single Comb White Leghorn chicks (Akita Co. Ltd., Hiroshima, Japan) were maintained in a room with $24-\mathrm{h}$ lighting and at a temperature of $30^{\circ} \mathrm{C}$. They were given free access to a commercial starter diet (Nichiwa Sangyo Co. Ltd., Kobe, Japan) and water during the pre-experimental period. They were distributed into experimental groups based on their body weight so that the average body weight was as uniform as possible for each treatment. The birds were reared individually in experimental cages and had ad libitum access to food up to the time of experiments. All experimental protocols were approved by the Animal Experiment Committee of Hiroshima University.

\section{Peptides and experimental procedure}

The following peptides were used: porcine insulin (MP Biomedicals Inc., Auroa, OH, USA), human insulin (Peptide Institute Inc., Osaka, Japan), and bovine insulin (Nacalai Tesque Inc., Kyoto, Japan). Chicken insulin was supplied by Dr. McMurtry. All peptides were dissolved in $0.85 \%$ saline containing $0.1 \%$ Evans Blue and $0.1 \mathrm{~N}$ HCL. Chicks (4-day-old) received an ICV injection of either insulin or vehicle solution $(10 \mu \mathrm{l} / \mathrm{bird})$ using a microsyringe according to the methods used by Davis et al. (1979). Each chick was injected once only with either peptide or vehicle solution.

Birds were given free access to food for $2 \mathrm{~h}$ immediately after each treatment. Food intake was determined by measuring the reduction in food consumption from a preweighed feeder. The weight of feeders was measured using an electric digital balance of precision $\pm 1 \mathrm{mg}$. In the first trial, ad libitum chicks were injected by the ICV route with one of three doses (0, 2 and $20 \mathrm{ng}$ ) of insulin (chicken, porcine, human or bovine). In the second trial, after being deprived of food for $3 \mathrm{~h}$ (to intensify hunger), birds were ICV injected with solution (control, $10 \mathrm{ng}$ chicken insulin or $10 \mathrm{ng}$ porcine insulin). The dose of insulin was determined according to the previous report (Shiraishi et al., 2008a).

At the end of the experiments, birds were sacrificed by decapitation, followed by brain sectioning to identify the location of the drug injection. Data were deleted from individuals in which the presence of Evans Blue dye in the lateral ventricle was not verified. The number of birds used for data analysis is shown in each figure.

\section{Statistical analysis}

Data were expressed as means \pm S.E.M. Statistical calculations were carried out using a repeated measures analysis of variance (RM-ANOVA), using the commercially available package, Stat View (Version 5, SAS Institute, Cary, USA, 1998). This analysis provides P-values for differences between treatment, differences over time, and for the interaction of treatment with time. When a significant interaction of treatment and time was documented, the Turkey-Kramer post hoc test was used to compare the significance among means at each time point. A P-value $<0.05$ was taken to indicate a significant difference.

\section{Results}

Figures 2, 3, 4 and 5 show the effects of ICV injection of the insulins on food intake in ad libitum-fed chicks. With chicken insulin (Fig. 2), RM-ANOVA for treatment (0, 2 and $20 \mathrm{ng}$ insulin) and time revealed a treatment (insulin) and time interaction ( $\mathrm{F}[6,66]=4.408, P<0.001)$, and main effects for treatment $(\mathrm{F}[2,22]=8.214, P=0.002)$ and time $(\mathrm{F}[3,6]=4.408, P<0.001)$. The highest dose (20 ng) of chicken insulin strongly suppressed food intake over $120 \mathrm{~min}$. The lower dose ( $2 \mathrm{ng}$ ) also shows a suppressive effect at $60 \mathrm{~min}$ post-injection, but not at $120 \mathrm{~min}$. With porcine insulin (Fig. 3), the main effect of treatment (insulin) was significant $(\mathrm{F}[2,13]=5.196, P=0.022)$, and an interaction between treatment and time was also significant $(\mathrm{F}[6,39]=3.146, P=0.013)$. Although a post hoc test did not detect any effect at 30 min post-injection, the higher dose (20 ng) significantly suppressed feeding behavior at 60 and $120 \mathrm{~min}$ when compared with control. With human insulin (Fig. 4), although $20 \mathrm{ng}$ of insulin tended to attenuate feeding behavior, a significant interac- 
Chicken

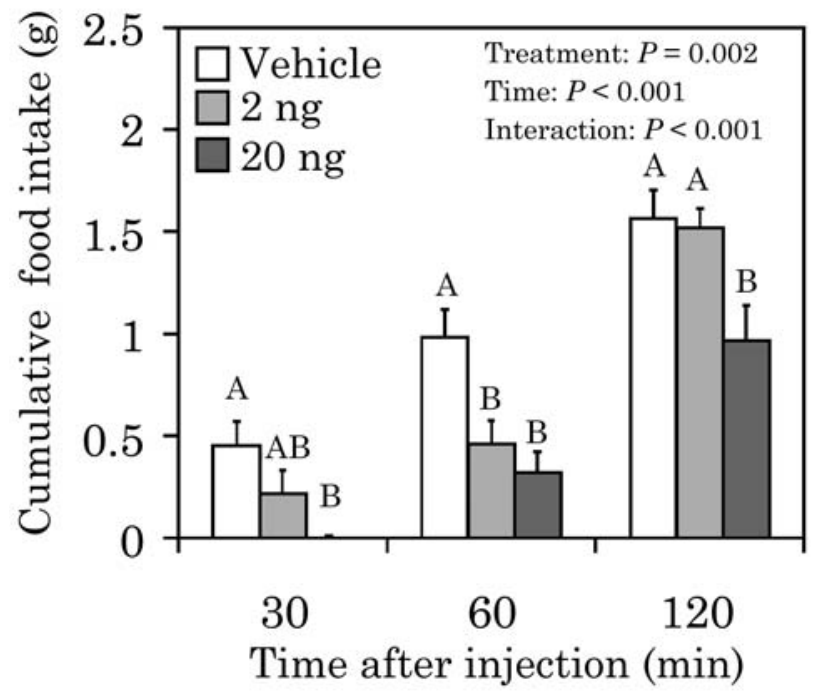

Fig. 2. Cumulative food intake of chicks injected ICV with vehicle or one of two doses of chicken insulin (2 or $20 \mathrm{ng})$. Data are presented as means \pm SEM. Means with different letters at each time are significantly different at $P<0.05$. The number of chicks used: vehicle, 10 ; chicken insulin $2 \mathrm{ng}$, 8; chicken insulin $20 \mathrm{ng}$, 7, respectively.

\section{Porcine}

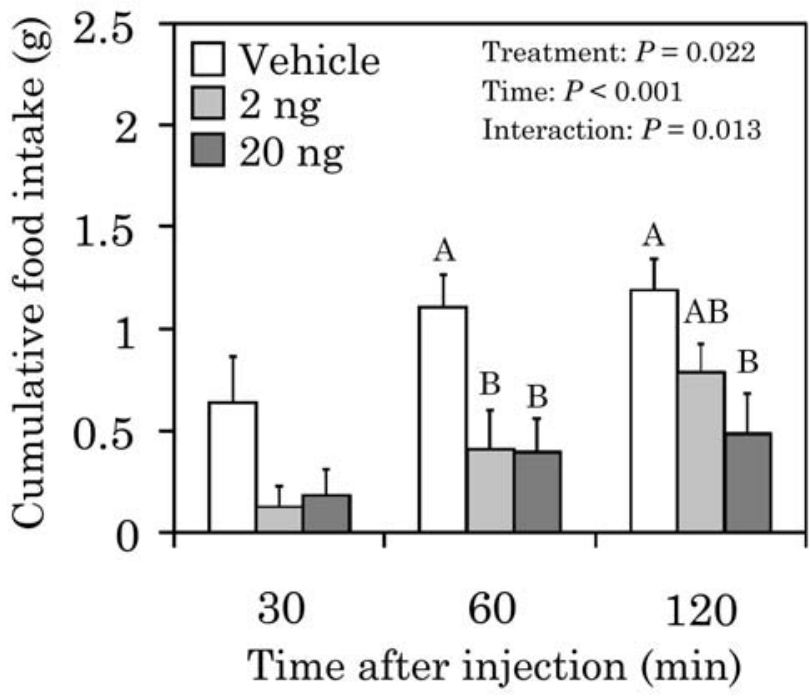

Fig. 3. Cumulative food intake of chicks injected ICV with vehicle or one of two doses of porcine insulin (2 or $20 \mathrm{ng})$. Data are presented as means \pm SEM. Means with different letters at each time are significantly different at $P<0.05$. The number of chicks used: vehicle, 6; chicken insulin $2 \mathrm{ng}$, 5; chicken insulin $20 \mathrm{ng}$, 5, respectively.

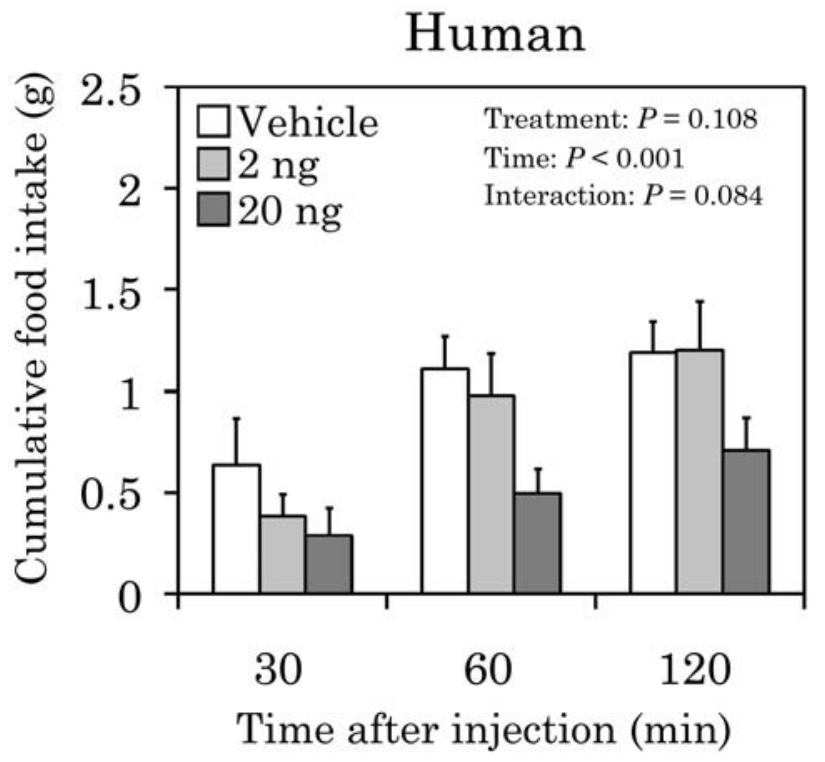

Fig. 4. Cumulative food intake of chicks injected ICV with vehicle or one of two doses of human insulin ( 2 or $20 \mathrm{ng})$. Data are presented as means \pm SEM. The number of chicks used: vehicle, 6 ; chicken insulin $2 \mathrm{ng}$, 6; chicken insulin $20 \mathrm{ng}, 6$, respectively.

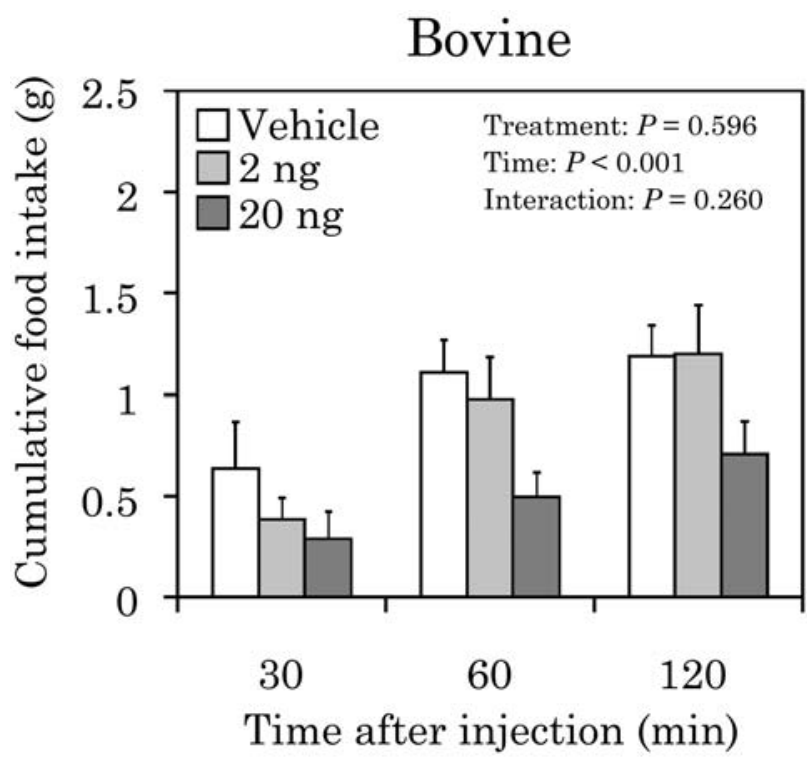

Fig. 5. Cumulative food intake of chicks injected ICV with vehicle or one of two doses of bovine insulin ( 2 or $20 \mathrm{ng})$. Data are presented as means \pm SEM. The number of chicks used: vehicle, 6; chicken insulin $2 \mathrm{ng}$, 6; chicken insulin $20 \mathrm{ng}, 6$, respectively. 


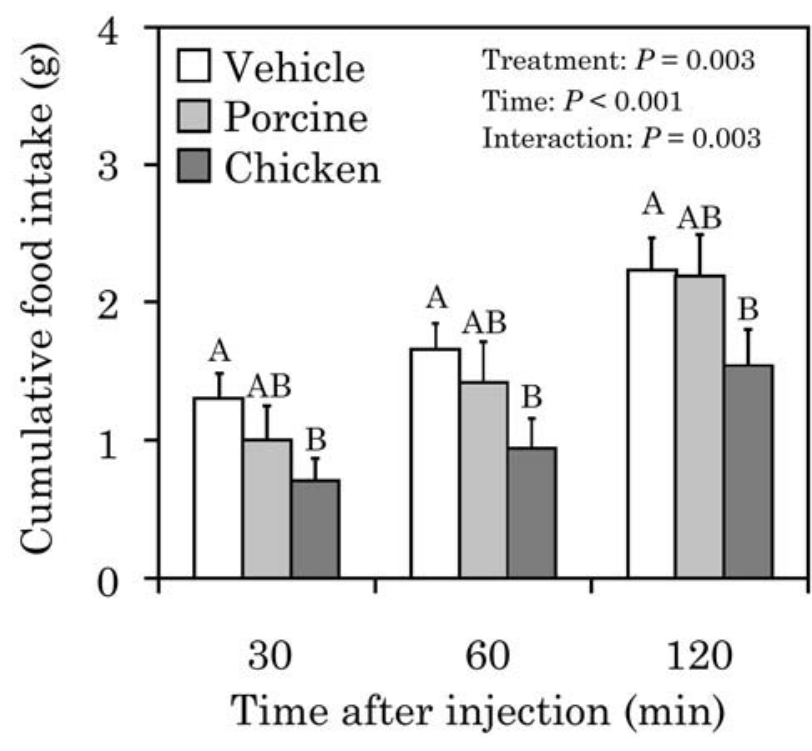

Fig. 6. Cumulative food intake of $3 \mathrm{~h}$ fasted chicks injected ICV with vehicle, porcine insulin (10 ng) or chicken insulin (10 ng). Data are presented as means \pm SEM. Means with different letters at each time are significantly different at $P<0.05$. The number of chicks used: vehicle, 7 ; porcine insulin $10 \mathrm{ng}, 8$; chicken insulin $10 \mathrm{ng}, 12$, respectively.

tion between treatment and time was not detected (F [6, $45]=2.011, P=0.08)$. The main effect of insulin was also not significant $(\mathrm{F}[2,15]=2.592, P>0.1)$. With bovine insulin (Fig. 5), both the effect for treatment $(F[2,15]=$ $0.536)$ and a treatment $\times$ time interaction $(F[6,45]=$ 1.340) were not significant $(P>0.1)$. Each level of insulin failed to suppress food intake in chicks during the 120-min period when compared with control.

Figure 6 shows the comparison of the effects of chicken and porcine insulin on feeding behavior in fasted chicks. Food intake in the chicken-insulin-treated group was significantly decreased over $120 \mathrm{~min}$ post-injection but porcine insulin failed to decrease deprivation-induced feeding in chicks at any time point when compared with control.

\section{Discussion}

Based on our results, it seems reasonable to conclude that the ranking in order of anorexic potency of the insulins on the chick brain is chicken insulin $>$ porcine insulin $>$ human insulin $>$ bovine insulin. Although the binding sites and/or the capacity of the $\alpha$ subunits of the central insulin receptor may be different from those in peripheral tissues (Simon and LeRoith, 1986; Mosthaf et al., 1990), our result is in good agreement with other reports: the ranking in order of affinity or potency is chicken insulin $>$ porcine insulin $>$ human insulin (Simon et al., 1974; 1977; Simon and LeRoith, 1986). Smith (1966) reported that there are six or seven variations out of the 51 residues of the molecule in chicken insulin compared with porcine, human or bovine insulin: in the A8-A10, B1, B2 and B27 compared with porcine and bovine insulin, and also in the B30 compared with human insulin (Fig. 1). The positions of $\mathrm{A} 8-\mathrm{A} 10$ have been suggested to be a critical immunogenic site of the molecule (Berson and Yalow, 1959; Wilson et al., 1962). The A8 site defines one edge of the classical receptor-binding surface of insulin and delimits the A1-A $8 \alpha$-helix (Pullen et al., 1976). In addition, the HisA8 analog (relative to ThrA8) enhanced thermodynamic stabilization (Chakrabartty et al., 1993), and the potency of glucose uptake in isolated adipocytes (Kaarsholm et al., 1993). Thus, the reasons why chicken insulin indicated higher biological potency than mammalian insulin might be that all of the amino acid residues at this site of chicken insulin are different from those of mammalian insulin and the presence of a histidine residue in chicken insulin at the A8 site.

We found that the effect of ICV administration of bovine insulin on food consumption is less potent than other mammalian insulin (Figs. 3-5). This is in good agreement with previous reports (Honda et al., 2007; Shiraishi et al., 2008a, b). However, the reaction of bovine insulin with human antiserums is higher than that of porcine insulin (Berson and Yalow, 1959), and the AlaA 8 analog had slightly higher potency of glucose uptake in isolated adipocytes than the ThrA8 analog (Kaarsholm et al., 1993). The reason for this discrepancy is not clear, but it might be caused by tissue-specific capacity of the $\alpha$ subunits of the insulin receptor (Mosthaf et al., 1990). The mutations of bovine insulin (combination of A8-A 10) might also affect the structure of $\alpha$ subunits and lower the affinity to chicken receptors when compared with porcine and human insulin.

The B-chain of chicken insulin displays three or four changes in 30 residues when compared to the mammal insulins used in the present report (Fig. 1). Bundell et al. (1972) indicated that positions B1, B2 and B27 seemed not to be directly involved in affecting the threedimensional configuration of the insulin monomer. The possibility that the difference of these positions greatly influenced our result was low. On the other hand, as for the difference in effectiveness between porcine insulin and human insulin (Figs. 3 and 4), there was only one variation between the two located at B30. Several studies have been made on immunological properties and biological effectiveness of insulin analogues at the $\mathrm{C}$ terminal of the B-chain. The cross reaction of desoctapeptide insulin (lack of B23-B30) was different from that of full-length insulin (Yalow and Berson, 1961; Karlsson et al., 1982). The substitutions in B30 lead to different results on both the antigenicity and immunogenicity of the insulin molecule (Neubauer et al., 1984). These reports imply that the changes in the amino acid sequence of B30 may influence the biological potency of insulin. Therefore, the $\mathrm{C}$ terminal of the B-chain might also be important in the biological potency of insulin in the chicken brain.

Taken together, the proper amino acid sequence of 
insulin may be necessary for the most effective interaction at the receptor site. Clearly, further work on the interaction of central insulin and insulin receptor functions or the structure of the $\alpha$ subunits of the receptor, is necessary in chickens. However, the results described here suggest that chicken insulin also exhibits greater potency than mammal insulin in the CNS of chicks.

\section{Acknowledgments}

This work was supported by a Grant-in-Aid for Scientific Research from the Japan Society for the Promotion of Science.

\section{References}

Berson SA, Yalow RS. Quantitative aspects of the reaction between insulin and insulin-binding antibody. The Journal of Clinical Investigation, 38: 1996-2016. 1959.

Blundell TL, Cutfield JF, Cutfield SM, Dodson EJ, Dodson GG, Hodgkin DC, Mercola DA. Three-dimensional atomic structure of insulin and its relationship to activity. Diabetes, 21: 492-505. 1972.

Chakrabartty A, Kortemme T, Padmanabhan S, Baldwin RL. Aromatic side-chain contribution to far-ultraviolet circular dichroism of helical peptides and its effect on measurement of helix propensities. Biochemistry, 32: 5560-5565. 1993.

Davis JL, Masuoka DT, Gerbrandt JF, Cherkin A. Autoradiographic distribution of L-proline in chicks after intracerebral injection. Physiology \& Behavior, 22: 693-695. 1979.

Harris JI, Naughton MA, Sanger F. Species differences in insulin. Archives of Biochemistry and Biophysics, 65: 427-438. 1956.

Hazelwood RL, Kimmel JR, Pollock HG. Biological characterization of chicken insulin activity in rats and domestic fowl. Endocrinology, 83: 1331-1336. 1968.

Hazelwood RL, Kimmel JR, Pollock HG. Influence of chicken and rat plasma on in vitro activity of chicken and beef insulin. Comparative Biochemistry and Physiology Part B, 39: 267-278. 1971.

Honda K, Kamisoyama H, Saneyasu T, Sugahara K, Hasegawa S. Central administration of insulin suppresses food intake in chicks. Neuroscience Letters, 423: 153-157. 2007.

Ishihara Y, Saito T, Ito Y, Fujino M. Structure of sperm- and sei-whale insulins and their breakdown by whale pepsin. Nature, 181: 1468-1469. 1958.

Kaarsholm NC, Norris K, Jørgensen RJ, Mikkelsen J, Ludvigsen S, Olsen OH, Sørensen AR, Havelund S. Engineering stability of the insulin monomer fold with application to structureactivity relationships. Biochemistry, 32: 10773-10778. 1993.

Karlsson F, Harrison LC, Kahn CR, Itin A, Roth J. Subpopulations of antibodies directed against evolutionarily conserved regions of the insulin molecule in insulin-treated patients. Diabetologia, 23: 488-493. 1982.

Kato H, Okubo Y, Matsumura Y, Roberts CT Jr, Sugahara K,
LeRoith D. The tyrosine kinase activity of the chicken insulin receptor is similar to that of the human insulin receptor. Bioscience Biotechnology and Biochemistry, 64: 903-906. 2000.

McMurtry JP, Rosebrough RW, Steele NC. A homologous radioimmunoassay for chicken insulin. Poultry Science, 62: 697-701. 1983.

Moller DE, Yokota A, Caro JF, Flier JS. Tissue-specific expression of two alternatively spliced insulin receptor mRNAs in man. Molecular Endocrinology, 3: 1263-1269. 1989.

Mosthaf L, Grako K, Dull TJ, Coussens L, Ullrich A, McClain DA. Functionally distinct insulin receptors generated by tissue-specific alternative splicing. The EMBO Journal, 9: 2409-2413. 1990.

Neubauer HP, Obermeier R, Schnorr G. Immunological properties and biological effectiveness of insulin analogues substituted at position B30. Diabetologia, 27: 129-131. 1984.

Nicol DS, Smith LF. Amino-acid sequence of human insulin. Nature, 187: 483-485. 1960.

Perler F, Efstratiadis A, Lomedico P, Gilbert W, Kolodner R, Dodgson J. The evolution of genes: the chicken preproinsulin gene. Cell, 20: 555-566. 1980.

Pullen RA, Lindsay DG, Wood SP, Tickle IJ, Blundell TL, Wollmer A, Krail G, Brandenburg D, Zahn H, Gliemann J, Gammeltoft S. Receptor-binding region of insulin. Nature, 259: 369-373. 1976.

Shiraishi J-i, Yanagita K, Fujita M, Bungo T. Central insulin suppresses feeding behavior via melanocortins in chicks. Domestic Animal Endocrinology, 34: 223-228. 2008a.

Shiraishi J-i, Yanagita K, Fujita M, Bungo T. $\mu$-opioid receptor agonist diminishes POMC gene expression and anorexia by central insulin in neonatal chicks. Neuroscience Letters, 439: 227-229. 2008b.

Simon J, Freychet P, Rosselin G. Chicken insulin: radioimmunological characterization and enhanced activity in rat fat cells and liver plasma membranes. Endocrinology, 95: 14391449. 1974.

Simon J, Freychet P, Rosselin G, DeMeyts P. Enhanced binding affinity of chicken insulin in rat liver membranes and human lymphocytes: relationship to the kinetic properties of the hormone-receptor interaction. Endocrinology, 100: 115-121. 1977.

Simon J, LeRoith D. Insulin receptors of chicken liver and brain. Characterization of alpha and beta subunit properties. European Journal of Biochemistry, 158: 125-132. 1986.

Smith LF. Species variation in the amino acid sequence of insulin. American Journal of Medicine, 40: 662-666. 1966.

Yalow RS, Berson SA. Immunologic aspects of insulin. American Journal of Medicine, 31: 882-891. 1961.

Wilson S, Dixon GH, Wardlaw AC. Resynthesis of cod insulin from its polypeptide chains and the preparation of cod-ox "hybrid" insulins. Biochimica et Biophysica Acta, 62: 483489. 1962. 